\title{
A ILEGALIDADE COMO FATOR PRECURSOR DA VIOLÊNCIA NA POLÍTICA DE DROGAS
}

ILLEGALITY AS A PRECURSING FACTOR OF VIOLENCE IN DRUG POLICY

Leonardo Cesar Gomes GARCIA ${ }^{1}$

ISSUE DOI: $10.21207 / 2675-0104.2017 .673$

\begin{abstract}
RESUMO
Inserida na legislação especial ou extravagante, a lei federal $\mathrm{n}^{\circ} 11.343 / 2006$, que dispõe e institui o Sistema Nacional de Políticas Públicas sobre Drogas (SISNAD) restou-se infrutífera frente ao propósito inicial a que se destinava. Se a vigente Lei de Drogas, editada no ano de 2006, almejava atenuar ou amenizar o excesso do punitivismo estatal, seu efeito prático acabou por vir em sentido oposto. O inchaço da população carcerária propiciou o surgimento das organizações criminosas, que comportam estatísticas alarmantes, sem olvidar os recentes massacres ocorridos em estabelecimentos prisionais, palcos de pavorosas violações contra os direitos humanos e constitucionais. Nesse diapasão, os resultados obtidos frente às reflexões objetivadas durante a presente reflexão evidenciaram o senso coletivo unânime e inexpugnável de que a Guerra às Drogas traduzida pelo modelo proibicionistabelicista, também conhecido como war on drugs, asseverou diversas precarizações sociais, dentre estas, a imensa intensificação do encarceramento brasileiro bem como o fomento da violência e injustiça social. Nada disso por si só, tem o condão de solucionar os efeitos da violência em torno das drogas, contudo, mostra-se indispensável o reconhecimento da concepção de que a existência de incoerências gravíssimas no ordenamento jurídico proporcionaram o surgimento de pessoas que, embora usam drogas, não praticam crime algum, enquantoa outras se valem das primeiras para cometer atos atrozes. Em meio à evidente dificuldade que enfrenta o intérprete da norma, tem-se inúmeros erros originados pela vã tentativa de manter uma imposição legal insustentável, que mesmo diante de seus reflexos negativos e destrutivos, ainda procura resistir.
\end{abstract}

Palavras-Chave: Punitivismo estatal; Guerra às Drogas; Belicismo; Crescimento da Violência Social.

\footnotetext{
${ }^{1}$ Discente da Faculdade de Direito de Franca/SP. Bolsista do Programa Interno de Iniciação Cientítica (PIBIC 2016-2017).
} 


\begin{abstract}
Inserted in special or extravagant legislation, Federal Law No. 11.343 / 2006, which has and establishes the National System of Public Policy on Drugs (SIS-NAD) was unsuccessful in view of its original purpose. If the current Drug Law, enacted in 2006, aimed to alleviate or soften the excess of state punitivism, its practical effect came in the opposite direction. The swelling of the prison population has led to the emergence of criminal organizations, which contain alarming statistics, without forgetting the recent massacres in prisons, stages of appalling violations of human and constitutional rights. In this tuning fork, the results obtained in the face of the reflections objectified during the present reflection evidenced the unanimous and unassailable collective sense that the War on Drugs, translated by the prohibitionist-warmonger model, also known as war on drugs, asserted several social precariousness, among these, the immense intensification of Brazilian incarceration as well as the fomentation of violence and social injustice. None of this in itself is capable of solving the effects of drug violence, however, it is indispensable to recognize the conception that the existence of very serious inconsistencies in the legal system led to the emergence of people who, although they use drugs, they do no crime, while others use the former to commit atrocious acts. Amid the evident difficulty facing the interpreter of the norm, there are numerous errors stemming from the vain attempt to maintain an unsustainable legal position, which even in the face of its negative and destructive reflexes, still seeks to resist.
\end{abstract}

Keywords: State Punitivism; War on Drugs; Warmongering; Growing Social Violence.

A pesquisa em questão está relacionada ao direito penal, mais precisamente aquele inserido na legislação especial extravagante que instituiu o Sistema Nacional de Políticas Públicas sobre Drogas (SISNAD), a saber, a lei federal $n^{\circ} 11.343 / 2006$. Busca-se através da problemática escolhida estabelecer e questionar a atual política vigente no que compete às substâncias ilícitas, bem como a sua relação para com o trágico fomento da criminalidade, sobretudo, a reflexão e debate sobre as novas diretrizes que devem ser pautadas e as inovações a serem alcançadas no que dispõe sobre o fracassado modelo de atuação vigente.

Tem-se que o ordenamento jurídico, marcado que foi pela evolução humana e das instituições que cercam o corpo social, acabou por adquirir uma maturidade de objeção e de questionamento frente referentes à forma de atuação repressiva e contrária ao modelo de estado que se busca conceber frente as normas pragmáticas adotadas pela magna carta, tratados e convenções internacionais.

Nesse diapasão, a legislação vigente sobre a política de drogas, acaba por legitimar e impulsionar a violência dentro de um contexto dramático de estratificação social e ausência de serviços básicos e políticas públicas em que se encontra o atual cenário nacional. 
Estabelecida essa premissa, procurar-se-á abordar, ao longo do presente artigo, o contexto histórico e jurídico das medidas que foram estabelecidas através do Estado, suas respectivas circunstâncias do cenário mundial frente a sintonia do modelo de combate capitaneado pelos Estados Unidos durante o surgimento crescente do consumo de drogas pela população e sua relação com a saúde pública.

Desse modo, o objetivo e foco do tema proposto é o aprofundamento teórico e científico no tocante aos reflexos do paradigma proibicionista, belicista e punitivista como promoção a violência estrutural, onde verificar-se-á o estabelecimento de um ciclo altamente vicioso de ações truculentas envolvendo a polícia representante do Estado e indivíduos que emergem de uma realidade social paralela às tradicionalmente concebidas pela sociedade, oriundas de organizações de poderes próprios e persuasivos, onde a razão instrumental e o meio, são determinantes para o desvio de conduta do cidadão.

Isto posto, passarão a ser analisadas as formas de discussão e combate ao pensamento atualmente concebido, baseado não mais num critério meramente punitivista, mas fundamentado na prática instrutiva educacional e preventiva, na regulamentação do uso, fabricação e distribuição das substâncias entorpecentes.

Indispensável se faz, ainda, no tocante à mudança da mentalidade e concepção acerca da figura do usuário, o qual, deve deixar de ser visto como um infrator do ordenamento, como agente passivo de políticas de tratamentos de saúde física e psíquica, com o intuito de se chegar a diminuição drástica do uso das mencionadas substâncias que contrapõemse ao desenvolvimento pleno da sociedade e seus indivíduos.

Pretende-se, ao final, levantar os aspectos históricos relativos ao surgimento da política antidrogas ainda em vigor para, assim, questioná-la e chamar a atenção da comunidade acadêmica e das entidades políticas e públicas, contribuindo para a construção da concepção da sociedade sobre os esclarecimentos da falibilidade do ordenamento frente aos fenômenos sociais decorrentes. 
Entende-se como entorpecente qualquer substância de ordem natural ou sintética capaz de provocar ou desencadear alterações físicas e psíquicas nos indivíduos que as ingerem, além de desencadear as hipóteses de dependência que se configuram em químicas ou psicológicas.

Assim, para que se caracterize ou classifique-se uma substância com a denominação de entorpecente, devem ser analisados os seus efeitos colaterais ou sintomas, de modo a concluir tenha ela ou não apresentado sinais de entorpecimento.

É o que, aliás, dispõe a lei no 11.343 , de 23 de agosto de 2006:

Art. $1^{\circ}$ Esta Lei institui o Sistema Nacional de Políticas Públicas sobre Drogas - Sisnad; prescreve medidas para prevenção do uso indevido, atenção e reinserção social de usuários e dependentes de drogas; estabelece normas para repressão à produção não autorizada e ao tráfico ilícito de drogas e define crimes.

Parágrafo único. Para fins desta Lei, consideram-se como drogas as substâncias ou os produtos capazes de causar dependência, assim especificados em lei ou relacionados em listas atualizadas periodicamente pelo Poder Executivo da União.

No que tange a esse conceito, a Organização Mundial da Saúde, considera serem as drogas, quaisquer substâncias não produzidas pelo organismo que tem a propriedade de atuar sobre um ou mais de seus sistemas, produzindo alterações em seu funcionamento.

Percebe-se, aí, e existência de divergência quanto à classificação do que sejam drogas.

A fim de auxiliar no estabelecimento de um conceito até certo ponto unívoco, procuramos nos valer da classificação que se baseia na distinção entre os efeitos das drogas sobre o sistema nervoso central (SNC) do indivíduo.

Ressalte-se, desde logo, a existência de variáveis nesse conceito, determinadas pelas características individuais dos usuários daquelas substâncias.

As drogas podem ser depressoras da atividade mental do indivíduo. Nessa classificação são incluídas uma variedade de substâncias, que se diferenciam em relação a sua composição química e física, porém no que diz respeito aos sintomas apresentados, exercem potencialmente 
efeitos estritamente semelhantes, como a diminuição de funções específicas ou afetando diretamente na atividade global. Trata-se inicialmente de aumento euforizante que posteriormente exerce demasiada sonolência ou indisposição, acarretando na diminuição da atividade motora, ansiedade e ritmo natural das funções cerebrais.

A título de exemplificação tem-se o álcool etílico, produto de fermentação encontrada em alguns vegetais, cuja utilização confunde-se com a história da humanidade, integrando uma linha estritamente tênue quanto a sua origem. A fermentação produz bebidas com proporção de até $10 \%$ (proporção do volume total de álcool na bebida), cumprindo salientar que as maiores porcentagens de álcool são obtidas através por meio da destilação.

O nível de substância alcoólica no sangue é crucial para determinar a fase de embriaguez bem como a variação em razão do tipo da bebida, da velocidade do consumo e também se aquele que o ingere comporta a presença de alimentos no estômago.

Em baixos níveis, as drogas com efeitos depressores causam a desinibição dos comportamentos, a diminuição da crítica, também apresentam hilaridade ou labilidade afetiva, uma vez que ri ou chora por motivos pouco significativos, segundo os quais frente à ausência de alguma substância depressora, não causariam o efeito apresentado.

Outro sintoma presente e que assevera a discussão acerca da proibição das drogas lícitas ou ilícitas depressoras diz respeito ao pequeno grau de ausência de coordenação motora ou prejuízo nas funções sensoriais. Diante do consumo médio ou auto, todos os sintomas são acentuados, acrescentando-se as náuseas e vômitos, visão dupla (diplopia) ou até mesmo acentuação da ataxia e da sonolência (até ao coma).

As drogas podem ser, também, estimulantes da atividade cerebral. São incluídas nessa classificação, aquelas substâncias capazes de aumentar as atividades de determinados sistemas neuronais, o que preconiza nos indivíduos que os ingerem determinado excesso de estado de alerta ou insônia, acelerando os processos psíquicos.

Tem-se a título de exemplificação o entorpecente cocaína, substância extraída de uma planta originária da América do Sul, popularmente conhecida como coca (Erythroxylon coca), responsável por grande parte das toxicomanias presentes na sociedade.

O mecanismo de ação que assevera sobre o corpo humano, sobretudo sobre o sistema nervoso central (SNC), fazendo com que o 
indivíduo que ingere supramencionada substância tenha sensação intensa de euforia e poder; estado de excitação; hiperatividade; insônia; falta de apetite e perda da sensação de cansaço.

Os indivíduos apresentam o desenvolvimento rápido da dependência, muitas vezes em poucos meses ou até mesmo em poucas semanas de uso. Com doses maiores prevalecem efeitos demasiadamente mais prejudiciais, tais como irritabilidade, agressividade bem como delírios de pânico e alucinações, caracterizando verdadeiro estado psicótico.

Outro aspecto relevante a ser considerado acerca das drogas estimulantes da atividade mental, trata-se dos graves riscos de infarto ou acidentes vasculares cerebrais (AVC), um processo de degeneração irreversível da musculatura (rabsomiólise) em usuários destas substâncias já foram descritos.

Existem, também, as drogas perturbadoras da atividade mental do indivíduo. Neste grupo, enquadram-se substâncias cujo efeito principal é o de provocar alterações estruturais no cérebro que resultam diversos fenômenos psíquicos anormais, entre os quais destaca-se os delírios e alucinações. No caso de delírio persecutório nota-se em toda parte indícios claros, embora irreais de perseguição contra a pessoa. Este tipo de fenômeno ocorre de modo espontâneo em certas doenças mentais denominadas psicoses, razão pelas quais essas drogas também são denominadas "psicotomiméticos".

O entorpecente ou substância nociva que bem ilustra a classificação em comento, pode ser usada como referência a maconha, o nome dado, no Brasil, à Cannabis Sativa L, suas folhas ou inflorescências secas podem ser fumadas ou ingeridas, a concentração de THC (Tetrahidrocanabinol), uma das diversas substâncias produzidas pela planta e que preconiza os diversos efeitos psíquicos. Efeitos que podem ser elencados desde os agudos aos crônicos, apresentam-se incialmente em alguns casos como a sensação de bem estar, acompanhada de calma e relaxamento, menos fadiga e hilaridade. Outros relatos atestam angústia, atordoamento, ansiedade e medo de perder o autocontrole, com tremores e sudorese.

O uso continuado interfere na capacidade de aprendizado e memorização, podendo induzir um estado de diminuição da motivação, chegando a síndrome amotivacional, uma vez que a pessoa não sente mais vontade de fazer nada. 
Em matéria de classificação, não se pode afirmar exista alguma que seja prevalente ou melhor. Faz-se necessária, contudo, a adoção de um critério, de modo a tratar de forma igual as situações semelhantes e, com isso, outorgar caráter científico à escolha procedida.

\section{A EVOLUÇÃO HISTÓRICA DA LEI DE DROGAS NO BRASL}

A presente incursão tem por objetivo elucidar o fundamento do debate acerca da realidade do status quo vigente quando da promulgação da vigente lei de drogas.

Sancionada em 23/08/2006, através da ratificação do presidente Lula, a ainda vigente lei número 11.343 passou a ter vigência em território brasileiro a partir do $2^{\mathrm{a}}$ semestre do ano de 2006.

$\mathrm{O}$ foco do escopo que fomentou a mudança bem como o modelo de atuação da antiga Lei de drogas baseava-se no binômio de duas faces, qual seja, o punitivo e médico.

Busca-se um mecanismo de atuação onde pudesse recrudescer as sanções para o tráfico de drogas e deslocar ou transferir o usuário de entorpecente das prisões para as redes de assistência médica e social, ou seja, um dispositivo capaz de exercer um modelo de atuação híbrido, médico-criminal.

Diante da contemplação de uma realidade consideravelmente oposta àquela cuja pretensão da lei de drogas se baseava, coube acometer o punitivísmo como objeto de fomento da delinquência, uma vez que a lei acaba por encarecer as mercadorias das substancias entorpecente, fazendo com que o risco das apreensões esporádicas seja acrescido e repassado ao consumidor final.

Sem olvidar a menção, no entanto, de que em virtude da norma imperativa, dispor sobre a proibição do consumo, criou-se em torno dessa, uma cadeia de violência, uma vez que em determinadas localidades do globo, sobretudo aquelas mais precárias, onde a atuação das garantias mínimas constitucionais que se obrigara em 1988 o estado não se atem, só resta o caminho da criminalidade.

Nesse diapasão, a nova lei de drogas, oriunda de um histórico de narrativas e discursos, com dispositivos e efeitos, deslocamentos bem 
como punições proporcionaram o presente caos como nos ensina Deleuze em suas palavras a respeito de Focault, dispondo que "a lei é a própria guerra". O mapa dos ilegalismos, todavia, continua a funcionar sob o modelo da legalidade. E Foucault mostra como a lei não é nem um estado de paz nem o resultado de uma guerra ganha: ela é a própria guerra e a estratégia dessa guerra em acto, exactamente como o poder não é uma propriedade adquirida da classe dominante mas um exercício actual de sua estratégia. (DELEUZE, 1987, P.53).

O surgimento da criminalização do uso, porte e comércio das substâncias entorpecentes no Brasil, tem sua origem remota quando da instituição das Ordenações Filipinas cujo teor indispensável se faz a menção. In Verbs: LIVRO V, TÍTULO LXXXIX - "que nínguém tenha em caza rosalgar, nem o venda, nem outro material venenoso"”.

Nesse ínterim, é correta a afirmação de que, embora sejam encontrados resquícios de disposições legais a respeito da proibição de substâncias psicotrópicas na evolução da história legislativa brasileira, somente nos anos 40 é que se objetiva por parte do poder público a objetivação ou compilação do surgimento da política proibicionista sistematizada.

As disposições repressivas encontram-se quando da autonomização das leis criminalizadoras (Decretos 780/36 e 2.953/38) bem como o polêmico ingresso do Brasil junto ao modelo internacional de controle (Decreto-Lei 891/38).

Os dispositivos supramencionados foram integralmente responsáveis pela criação da potencialização das leis penais repressivas que criavam através de um discurso Médico-Jurídico e Ético-Jurídico o estereótipo moral do consumidor.

O consumo de drogas se comparado relativamente a um passado recente no Brasil, sempre esteve associado aos movimentos de contestação ou contracultura que surgiram durante os anos 60, principalmente no que diz respeito ao consumo e popularização da Maconha e do LSD, estes eram utilizados como instrumentos de protestos contra a ordem vigente bem como em face das políticas belicistas e armamentistas.

Sempre em conjunto com outros elementos de manifestações ideológicas como a música, artes, cinema, vestuário e sexualidade, parcelas da sociedade recorreram destes mecanismos para a imposição de movimentos de ruptura em contrariedade aos regimes totalitários que se instalavam frente a vigência do cenário internacional. 
Nesse diapasão como imediata resposta das instituições jurídicas e políticas governamentais, frente aos movimentos iniciados, buscou-se sustentar o discurso autoritário seguindo dos movimentos de Lei e Ordem (MLOs) como plano de ações de ideologias negativas cuja função é precipuamente intensificar o combate à marginalidade, valendo-se da mídia como meio de produção em massa e outros meios de comunicação capazes de orientar unilateralmente o senso comum este polo passivo das informações ventiladas.

A partir das análises das descrições das alterações ocorridas na legislação vigente no Brasil, é possível aferir que a diminuição da monta do encarceramento prescindiria quase que exclusivamente da ampla reforma no quadro legislativo objetivando reflexos frente a totalidade das fases da persecução criminal, qual seja, da investigação policial até a execução da pena. Isto posto, a modificação estrutural colocaria por fim o triste quadro histórico das taxas de encarceramento que por si só reflete na exclusão social e inclusão prisional que quase que exclusivamente vislumbra somente um biótipo de cidadão, aqueles de maiores vulnerabilidades, que não goza das tutelas estatais, ou seja, não usufrui dos mínimos direitos segundo os quais a constituição de 1988 visava assegurar.

Buscou-se estabelecer e questionar a atual política vigente no que compete às substâncias ilícitas, bem como a sua relação para com o trágico fomento da criminalidade.

Indispensável se faz a reflexão e sobre a execução desta política que transformou o Brasil na quarta maior população carcerária do mundo de acordo com os últimos dados divulgados pelo Ministério da Justiça e o Departamento Penitenciário Nacional (DEPEN) em 2014, que apontou a quantia de 622.202 mil presos, resultantes do aumento de $267,32 \%$ nos últimos quatorze anos, sendo a lei de drogas responsável por $28 \%$ dos brasileiros que estão no cárcere que por sua vez nesta proporção, resultará em 2050 ao Brasil, a maior população carcerária mundial.

Em algumas varas criminais brasileiras e câmaras dos tribunais, os processos envolvendo a criminalização das drogas representam $50 \%$ do volume de trabalho. 
A atual legislação que dispõe sobre a postura das instituições frente a problemática social dos entorpecentes possui caráter dualístico, uma vez que busca prevenir e recuperar o usuário de entorpecente (a aplicabilidade do saber médico para o usuário de drogas), conjuntamente ao caráter repressivo e criminal (a fim de prender e combater o indivíduo que comercializa a droga).

Ocorre que, no que compete ao intuito médico preventivo, este se mostra profundamente infrutífero e estático cuja sua aplicabilidade concentrou-se em apenas um aspecto do escopo do plano de ação da intenção do legislador, qual seja, punitivismo, repressão e belicismo.

A esse propósito indispensável se faz a analogia do filósofo Foucault:

Sem dúvida a delinquência é uma das formas de ilegalidade; em todo caso, tem suas raízes nela; mas é uma ilegalidade que o sistema carcerário, com todas as suas ramificações, investiu, recortou, penetrou, organizou, fechou num meio definido e ao qual deu um papel instrumental, em relação às outras ilegalidades. Em resumo, se a oposição jurídica ocorre entre a legalidade e a prática ilegal, a oposição estratégica ocorre entre as ilegalidades e a delinquência [...] A penalidade de detenção fabricaria - daí sem dúvida sua longevidade - uma ilegalidade fechada, separada e útil. (FOUCAULT,2003, p.230231).

Os efeitos penitenciários provocados pela política bem como as diretrizes em comento, são evidenciados pelas informações penitenciárias que embora divulgadas somente no ano de 2014 , elucidam a seletividade penal.

Logo, tratando-se de punitivismo estatal tem-se o surgimento do benefício disposto na legislação pertinente, qual seja, o tráfico privilegiado, onde devemos examinar o caso sob o crivo da recente decisão do Supremo Tribunal Federal (HC 118533 MS) o qual afastou o caráter hediondo do referido delito, sendo possível desse modo a fixação do regime inicial aberto para o início do cumprimento da reprimenda.

Da mesma forma, caberá a substituição da pena privativa de liberdade por restritivas de direitos, conforme reiterada e pacificamente decidido pelo egrégio Superior Tribunal de Justiça: 
HABEAS CORPUS. CONSTITUCIONAL. PENAL. TRÁFICO DE DROGAS. CAUSA ESPECIAL DE REDUÇÃO DE PENA PREVISTA NO ART. 33, § $4^{\circ}$, DA LEI 11.343/06. APLICAÇÃO DA LEI 8.072/90. MATÉRIA AFETADA AO PLENÁRIO NO HC 110.884. AFETAÇÃO DA PRESENTE IMPETRAÇÃO PARA JULGAMENTO CONJUNTO. 1. Habeas corpus, com pedido liminar, impetrado pela DEFENSORIA PÚBLICA DA UNIÃO, em favor de RICARDO EVANGELISTA VIEIRA DE SOUZA E ROBINSON ROBERTO ORTEGA, tendo como objeto o Recurso Especial n. 1.297.936, julgado pela Quinta Turma do Superior Tribunal de Justiça, Relator o Ministro Marco Aurélio Bellizze. 2. Discute-se, no presente habeas corpus, a natureza hedionda ou não do crime de tráfico de drogas, com a incidência da causa de diminuição de pena prevista no art. $33, \S 4^{\circ}$, da Lei n. 11.343/2006. Decisão: O Tribunal, por maioria e nos termos do voto da Relatora, concedeu a ordem para afastar a natureza hedionda do tráfico privilegiado de drogas, vencidos os Ministros Luiz Fux, Dias Toffoli e Marco Aurélio. Reajustaram os votos os Ministros Edson Fachin, Teori Zavascki e Rosa Weber. Ausente, nesta assentada, o Ministro Gilmar Mendes. Presidiu o julgamento o Ministro Ricardo Lewandowski. Plenário, 23.06.2016.

Isto posto, a demonstração do crime de tráfico de drogas necessita de elemento probatório mínimo e firme que demonstre e comprove as condutas delitivas que estão elencadas pelos verbos nucleares do tipo objetivo do artigo 33, caput, da Lei $\mathrm{n}^{\circ} 11.343 / 06$, ou seja, são necessárias provas suficientes de que a droga era destinada ao comércio e venda, em suma, a disseminação do entorpecente, que, todavia, se mostra discricionária quando aplicada ao caso concreto.

O próprio Tribunal de Justiça de São Paulo, quando assim instado a se manifestar em duas oportunidades, asseverou que a mera apreensão da droga não é suficiente para configurar o delito de tráfico de entorpecentes, sendo necessário um mínimo de outros elementos que sejam aptos a fazer gerar a situação de traficância e, com isso, formar o convencimento da autoridade, seja policial ou judiciária: 
PROVA TÃO SOMENTE DA APREENSÃO DO TÓXICO - INSUFICIÊNCIA PARA CONFIGURAR O COMÉRCIO DESCLASSIFICAÇÃO PARA A POSSE DE ENTORPECENTE - RECURSO PARCIALMENTE PROVIDO. Não basta a apreensão - seja de quantidade for - de material entorpecente, para a caracterização do tráfico, sendo necessário um mínimo de outros elementos formadores do convencimento (TJSP - AC 125/764-3/9. Rel. RENATO NALINI, in RT 693/338 e RJTJSP 136/495) No mesmo sentido: RT 518/378, 671/368 e RJTJSP 124/511, 139/270-290).

TRÁFICO DE DROGAS - DESCLASSIFICAÇÃO PARA PORTE ILÍCITO DE ENTORPECENTES PARA USO - APELO DO MINISTÉRIO PÚBLICO - RECURSO IMPROVIDO ANTE A NÃO COMPROVAÇÃO DA MERCANCIA ILÍCITA Cabível a desclassificação do crime de tráfico ilícito de entorpecentes para porte para uso, previsto no artigo 28 da Lei $\mathrm{n}^{\circ} 11.343 / 2006$, quando ausente a prova da mercancia da droga ilícita pelo sentenciado, usuário de drogas". (TJSP, Processo 00058284220148260533, Relator Willian Campos, Julgamento: 10/12/2015, Órgão Julgador: $15^{\mathrm{a}}$ Câmara de Direito Criminal, Publicação: 15/12/2015).

Não só aquele Tribunal, mas outros espelhados pelo Brasil têm reconhecido que a não comprovação do tráfico de drogas enseja a desclassificação do delito de tráfico para o de consumo, previsto no art. 28, caput, da Lei de Drogas:

PENAL E PROCESSUAL PENAL. APELAÇÃO CRIMINAL. ABSOLVIÇÃO DO RÉU DA IMPUTAÇÃO DO CRIME TRÁFICO ILÍCITO DE ENTORPECENTES. DESCLASSIFICAÇÃO PARA CONSUMO. RECURSO MINISTERIAL. NÃO COMPROVAÇÃO DA CONDUTA DE TRÁFICO. NA DUVIDA, RESOLVE-SE EM FAVOR DO RÉU. RECURSO IMPROVIDO. 1. Para um édito condenatório é necessária a certeza, e não apenas conjecturas quanto à autoria. Assim, não sendo possível extrair-se do conjunto probatório prova de 
que o apelante tenha cometido o delito de tráfico narrado na denúncia, deve ser mantida a sentença que desclassificou o delito para o do art. 28 da Lei11.343/06.2. À unanimidade, foi negado provimento ao apelo ministerial. (TJPE, Processo APL 3495585, Relator Mauro Alencar de Barros, Julgamento: 15/12/2015, Órgão Julgador: $2^{a}$ Câmara Criminal, Publicação: 20/01/2016).

APELAÇÃO - TRÁFICO DE DROGAS - NÃO COMPROVAÇÃO DA MERCANCIA ESTABILIDADE NÃO COMPROVADA DESCLASSIFICAÇÃO MANTIDA. Inexistindo nos autos provas seguras a demonstrar, sem qualquer resquício de dúvida, que a substância entorpecente apreendida se destinava à traficância, bem como a estabilidade necessária para se comprovar a associação entre os agentes para a configuração do delito de associação, é de rigor a desclassificação da conduta para o artigo 28 da Lei 11.343/06. TJMG, Processo APR 10148110023154001 MG, Relator Paulo Cézar Dias, Julgamento: 29/01/2013, Órgão Julgador: Câmaras Criminais Isoladas/3 ${ }^{\mathrm{a}}$ Câmara Criminal, Publicação: 05/02/2013).

A fim da mantença da ordem e controle de constitucionalidade não cabe a um dos poderes usurpar a competência de outro no que diz respeito à flexibilização do modo de aplicação do ordenamento jurídico tendo como propósito exclusivamente uma crise vivenciada. É necessário buscar o foco do caos, estabelecer uma nova legislação.

O cerne da questão, contudo, trata-se de qual política alternativa a ser adotada, o ativismo judiciário frente às dificuldades repercutidas busca através de medidas e decisões progressistas reequilibrar a questão, sentenças com efeito vinculante estão por criarem precedentes que amenizem o óbice em comento.

A título de exemplificação, as recentes decisões de que o tráfico privilegiado não é crime hediondo, ou que o Estado deve indenizar por danos morais o detento em más condições de saúde e higiene ou superlotação, ou que a prisão preventiva não pode ser decretada de modo automático em ocorrências envolvendo o crime de tráfico (Art. 33, caput da lei 11.343/2006), acabam por evidenciar o descontrole institucional frente a temática carcerária, perplexidade esta, questionada pelo ministro 
do Supremo Tribunal Federal (STF) Gilmar Mendes durante o seminário sobre os 10 anos da lei que instituiu o Sistema Nacional de Políticas Públicas sobre Drogas: "A suprema corte de um país pode alterar a decisão tomada pelo legislador?".

Ademais, a flexibilização social fez com que o judiciário se mobilizasse no sentido de alterar o norte da aplicação em contexto.

Vale salientar, de pronto, a seriedade da tese ora ventilada, eis que o Supremo Tribunal Federal, ao realizar o exame prévio de admissibilidade do Recurso Extraordinário $n^{\circ}$ 635.659, interposto pela Defensoria Pública do Estado de São Paulo, reconheceu que a matéria tem repercussão geral, extravasando o âmbito de interesse das partes naquele processo.

O legislador ordinário, quando redigiu o artigo 28 da Lei $\mathrm{n}^{\circ}$ 11.343/2006, sancionando as condutas de quem possui ou detém de qualquer forma drogas para seu consumo próprio, extrapolou seu poder, ferindo preceitos constitucionais que condicionam a atividade legiferante.

De fato, o artigo $5^{\circ}$, inciso X, da Constituição Federal, positivou o direito fundamental de todo e qualquer cidadão à inviolabilidade da intimidade, da vida privada, da honra e da imagem.

Esse direito tem reflexos na esfera penal, na medida em que somente é legítima a relativização de uma garantia individual fundamental se ela for necessária para que outra pessoa usufrua de seus direitos, compatibilizando, portanto, interesses antagônicos dos componentes da sociedade.

\section{A NECESSIDADE DE TRANSFERÊNCIA E ENQUADRAMENTO DA LEGISLAÇÃO VIGENTE: A MUDANÇA DO EIXO PUNITIVISTA E BELICISTA}

A mudança do foco do âmbito criminal é o ponto de partida para que sejam estabelecidas novas diretrizes. Destarte as nações inclusas em uma conjuntura política transnacional, antes de tudo, precisam adotar os modelos que possuem um efeito prático positivo.

O globo tem vivenciado experiências de outras nações, inclusive recentemente. Exemplo disso é o Uruguai, país da América do Sul, em que 
vem sendo implementada uma nova extrapragmática sobre o reflexo das drogas na sociedade.

É necessário ressaltar, desde logo, que não existe uma solução pré-concebida. Assim, faz-se imperiosa a adoção de novos modelos em que o processo de experimentação passará a gerar o aperfeiçoamento das medidas.

Até o presente instante, o modelo político que vem ganhando espaço no cenário mundial é o da política da redução de danos ou a estratégia de redução de danos.

Oriunda de experiências oriundas de países da Europa, tende-se a verificar que o usuário, uma vez que seja criminalizado, tenderá a se afastar do Estado e, consequentemente, o consumo no mercado ilegal e clandestino restará como a sua única opção.

Assim, enquanto existir demanda, haverá oferta.

Busca-se frente a essa nova política através de mecanismos executados pela Saúde Pública de que o indivíduo que faz o uso de drogas o faça sob a supervisão do estado, tutelando-o para que o faça com os menores danos possíveis.

\section{CONSIDERAÇÕES FINAIS}

Por todo o exposto, faz-se imprescindível a adoção de um modelo de políticas públicas especificamente voltada à questão das drogas, que seja voltada à realidade nacional.

Isso porque, como se viu, a adoção da teoria da abstinência objetiva pela ideologia norte-americana, apenas tem o condão de agravar os os sintomas do punitivismo e do belicismo, representando verdadeira política de higienização de raças e extermínio das camadas sociais vulneráveis.

Atualmente, a redução de danos depara-se com infindáveis desafios, que demandam uma compreensão expandida do fenômeno social das drogas no contemporâneo, a fim de elucidar ações diversificadas que vão além do uso e porte de pequenas quantidades de drogas injetáveis e da prevenção de doenças infecciosas.

É preciso objetivar um escopo mais acurado e específico sobre a configuração atual do cenário das drogas no País e responder às atuais 
demandas no campo da prevenção, como o álcool e o crack. Para tanto, necessita-se de um envolvimento conjunto de diferentes setores da sociedade e de instituições como, por exemplo, a escola, da articulação e da divisão de responsabilidades entre os campos da saúde e da segurança, além da reconstrução do enfoque sobre as drogas propagado pelos meios de comunicação de massa2.

Nesse passo, todo o debate atual, decorrente da possível falta de clareza sobre a redução de danos, seja no âmbito acadêmico, seja na prática, indica que a superação dos entraves entre segurança e saúde somente foi efetivada no plano teórico, e ainda assim, apenas parcialmente, pois, na prática, essas duas esferas continuam ambíguas.

Não se pode dizer que a saúde tenha superado os entraves da segurança pública e da Justiça na questão das drogas, uma vez que as experiências ainda demonstram falta de clareza sobre os âmbitos de intervenção de cada uma dessas áreas e a contradição das concepções sobre o fenômeno das drogas entre os dois lados ${ }^{3}$.

\section{REFERÊNCIAS BIBLIOGRÁFICAS}

ALVES, V. S. (2009). Modelos de atenção à saúde de usuários de álcool e outras drogas: discursos políticos, saberes e práticas. Cadernos de Saúde Pública, 25(11), 2309-2319.

AYRES JÚNIOR, J. R., , I. F., Calazans, G. J., \& Filho, H. C. (2003). O conceito de vulnerabilidade e as práticas de saúde: novas perspectivas e desafios. In D. Czeresnia (Org.), Promoção da saúde: conceitos, reflexões, tendências (pp. 117 - 139). Rio de Janeiro: Fiocruz.

BRASIL. (1938). Decreto-lei no 891, de 25 de novembro de 1938. Aprova a Lei de Fiscalização de Entorpecentes. Recuperado em 14 outubro, 2010, de http://www.planalto.gov.br/ccivil/Decreto-Lei/1937-1946/Del0891.htm. [ [ Links ]

\footnotetext{
2 MACHADO, Letícia Vier; BOARINI, Maria Lúcia. Política de Drogas no Brasil: A estratégia de Redução de Danos. 2013. 33 v. Tese (Doutorado) - Curso de Direito, Universidade Estadual de Maringa, Brasil, 2013. Disponível em: <http://www.scielo.br/pdf/pcp/v33n3/v33n3a06.pdf>. Acesso em: 05 nov. 2017.

${ }^{3}$ MACHADO, Letícia Vier; BOARINI, Maria Lúcia. Política de Drogas no Brasil: A estratégia de Redução de Danos. 2013. 33 v. Tese (Doutorado) - Curso de Direito, Universidade Estadual de Maringa, Brasil, 2013. Disponível em: <http://www.scielo.br/pdf/pcp/v33n3/v33n3a06.pdf>. Acesso em: 05 nov. 2017.
} 
CAMPOS, Marcelo da Silveira. As principais implicações da nova lei de drogas no sistema de justiça criminal em são paulo. 2015. 313 f. Tese (Doutorado) - Curso de Sociologia, Usp, São Paulo, 2015. Disponível em:

<file:///D:/Documentos.Locais/Downloads/2015_MarceloDaSilveiraCampos_VOrig.pdf>. Acesso em: 05 jul. 2017.

FOUCAULT, Michel. igiar e punir: nascimento da prisão. Trad. Raquel Ramalhete. Petrópolis: Vozes, 1987.

MACHADO, Letícia Vier; BOARINI, Maria Lúcia. Política de Drogas no Brasil: A estratégia de Redução de Danos. 2013. 33 v. Tese (Doutorado) - Curso de Direito, Universidade Estadual de Maringa, Brasil, 2013. Disponível em:

<http://www.scielo.br/pdf/pcp/v33n3/v33n3a06.pdf>. Acesso em: 05 nov. 2017.

SHECAIRA, Sergio Salomao. Criminologia. 2.ed. São Paulo: Revista dos Tribunais, 2008 . 